\title{
Endoscopic Removal of Clival Chordoma
}

\author{
1 Jitendra S Yadav, ${ }^{2}$ Vineet Kumar, ${ }^{3}$ Siva Selvaraj, ${ }^{4}$ Chander Bhan, ${ }^{5}$ Manish Pandey
}

\begin{abstract}
Clivus chordomas are locally aggressive benign, with primary bone tumor arising from remnant of notochord anywhere from the coccyx to the base of the skull, in either a midline or paramedian position. The tumors show rare presentation and relatively common recurrence rate. Intracranial chordomas usually arise from the region around the clivus and account for about a third of all chordomas. Clival chordomas rarely metastasize and become symptomatic after local invasion to cranial nerves and skull base structure. Diagnosis is based on computed tomography scan/magnetic resonance imaging findings and histopathological examination of soft tissue mass. Complete surgical resection is the primary line of management with or without radiotherapy. We are presenting a case of clival chordoma of a 35-year-old female who presented with diminished vision and headache since 6 months. After evaluation, the patient was treated with endoscopic endonasal transsphenoidal resection of the tumor. After surgery, the patient showed relief from headache and slight improvement in vision loss.
\end{abstract}

Keywords: Clival chordoma, Endonasal, Endoscopic, Transsphenoid approach.

How to cite this article: Yadav JS, Kumar V, Selvaraj S, Bhan C, Pandey M. Endoscopic Removal of Clival Chordoma. Clin Rhinol An Int J 2017;10(1):28-31.

\section{Source of support: Nil}

Conflict of interest: None

\section{INTRODUCTION}

The clivus is the unpaired basilar portion of the occipital bone extending obliquely from the anterior aspect of the foramen magnum up to the basisphenoid bone just inferior to the dorsum sella. Hence, clival chordomas are midline structures projecting posteriorly and compressing the nearby structures. ${ }^{1}$ Hence, spheno-occipital chordomas are also called as "clival chordomas" and the most common presenting symptoms are headache (50\%), visual complaints, facial pain, numbness or paresthesia $(50 \%)$, and diplopia $(42 \%)$. Other nonspecific symptoms of chordomas are dysphagia and dysarthria, ataxia, extreme weakness, and hoarseness.

\footnotetext{
${ }^{1}$ Assistant Professor, ${ }^{2,3,5}$ Junior Resident, ${ }^{4}$ Senior Resident

${ }^{1-5}$ Department of ENT, Maharani Laxmibai Medical College Jhansi, Uttar Pradesh, India
}

Corresponding Author: Vineet Kumar, Junior Resident Department of ENT, Maharani Laxmibai Medical College Jhansi, Uttar Pradesh, India, Phone: +917084350583, e-mail: vineet_kumar21@yahoo.com
Chordomas are rare, slow-growing benign tumors of the bone that account for $4 \%$ of all primary bone tumors. ${ }^{2}$ These tumors arise from the remnants of primitive notochord, which extend from the Rathke's pouch at skull base to the coccyx. The cranial and caudal end of the spine are the most commonly affected areas due to nests of notochordal cells behind the clivus and the sacrococcygeal regions, while the remainder of the notochord regresses during fetal life.

Incidence is less than $0.1 / 100,000$ of population. ${ }^{3}$ Mean age of presentation is 47 years ( $8-80$ years). Incidence is slightly more in male. Sacral-coccygeal chordomas (50$60 \%$ ) are the commonest type of presentation, followed by skull base or spheno-occipital chordomas (25-35\%) and the cervical vertebral chordomas (approximately $10 \%$ ). ${ }^{4}$

Chordomas of skull base usually occur in patients of 20 to 40 years of age, whereas sacrococcygeal chordomas are typically seen in an older age group of around 50 years. $^{2,3}$ These are locally aggressive and erode the surrounding bones and rarely metastasize to distant sites over a period of time. ${ }^{5}$

\section{CASE REPORT}

A 35-year-old female patient presented to our ear, nose, and throat outpatient department with complaint of headache for the past 7 years and left side blindness with right side diminished vision, which was progressively increasing in the last 6 months. Headache was spontaneous, continuous, dull aching, holocranial, slowly progressive in severity, and was not associated with vomiting. She developed spontaneous, painless, progressive diminished vision in the left eye. She gave no significant past medical or surgical history.

Detailed history was taken and general examination was done. Bilateral diminished vision, more on the left side, was present. Bilateral fundus examination was normal. Visual evoked potential was done, which showed nonrecordable waveform on left side and normal P100 latency with borderline reduced amplitude in the right side. No other significant clinical finding was present.

On radiological examination, computed tomography (CT) paranasal sinuses (PNS) (Fig. 1) and magnetic resonance imaging (MRI) (Figs 2A and B) showed large altered signal intensity mass lesion occupied bilateral sphenoid and posterior ethmoid air cells. No obvious bony erosion of anterior, midcranial fossa, or intracranial 


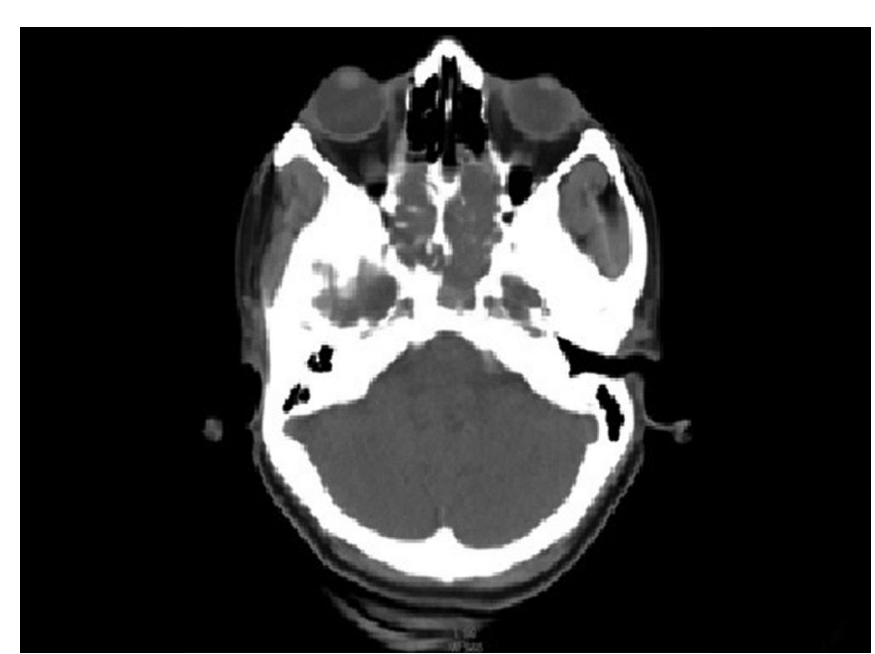

Fig. 1: Contrast-enhanced CT brain with PNS in axial section showing large destructive lytic soft tissue mass involving body of sphenoid extending into middle cranial fossa posteriorly and anteriorly into bilateral ethmoid sinuses

extension was seen. Pituitary gland appears normal and was pushed posterosuperiorly. Mass lesion causes bony remodeling of posterior end of bilateral medial orbital wall and bulging it laterally (more on left side). Lesions appear to be compressing bilateral optic nerve. These findings were suggestive of clival chordoma.

After complete evaluation, endoscopic endonasal transsphenoidal removal of the tumor mass from the clivus under general anesthesia was done. During surgery, the tumor was approached through the sphenoid sinus and the tumor was totally removed in small pieces by curetting and chiseling out along with pterygoid plate. Dura and optic nerve was exposed, which was found to be intact. The residual space and defect in dural plate was closed with fat graft taken from the abdominal wall and Hadad-Bassagasteguy flap ${ }^{6}$ to prevent cerebrospinal fluid leak in case if it happens and to protect the intracranial tissue. The surgery was uneventful. No neurological deficits were seen after the surgery. Patient recovered well in the postoperative period with complete relief from headache and slight improvement in vision, and was discharged after 10 days of surgery. Postoperative CT PNS was done and no abnormality was detected. Histopathological report of the surgical specimen shows physaliferous cells separated by fibrous and myxoid stroma, suggestive of chordoma (Fig. 3).

\section{DISCUSSION}

In the 1980s, only 3 cases of clival chordoma were reported, whereas there were 8 cases in the 1990s, 27 cases in the 2000s, and an additional 9 from 2011 to 2013. This increasing number of clival chordoma reporting may be due to increasing number of literature on this disease, modern diagnosing modalities like CT scan and MRI, modern surgical interventions with the introduction of endoscopic endonasal approaches (EEAs) to the clivus, and increasing longevity of patients.

Clinical presentation of clival chordomas varies according to the location and size of the tumors. ${ }^{3}$ Symptoms are due to the mass effect on adjacent structures. ${ }^{2}$ They present with cranial nerve palsies presenting as visual disturbances or loss of vision, orbitofrontal headache, loss of facial sensation, voice change and difficulty in swallowing, neck pain, and intracranial hemorrhages. ${ }^{8-10}$ But they can also remain silent for a long duration as they are slow growing and can pose difficulty and delay in diagnosis of the disease.

The CT scan and MRI play a very important role in the diagnosis and evaluation of the clival chordoma: CT scan helps to detect any bony erosion by the tumor and the degree of ossification within the tumor, whereas MRI helps in analyzing the brainstem involvement better than
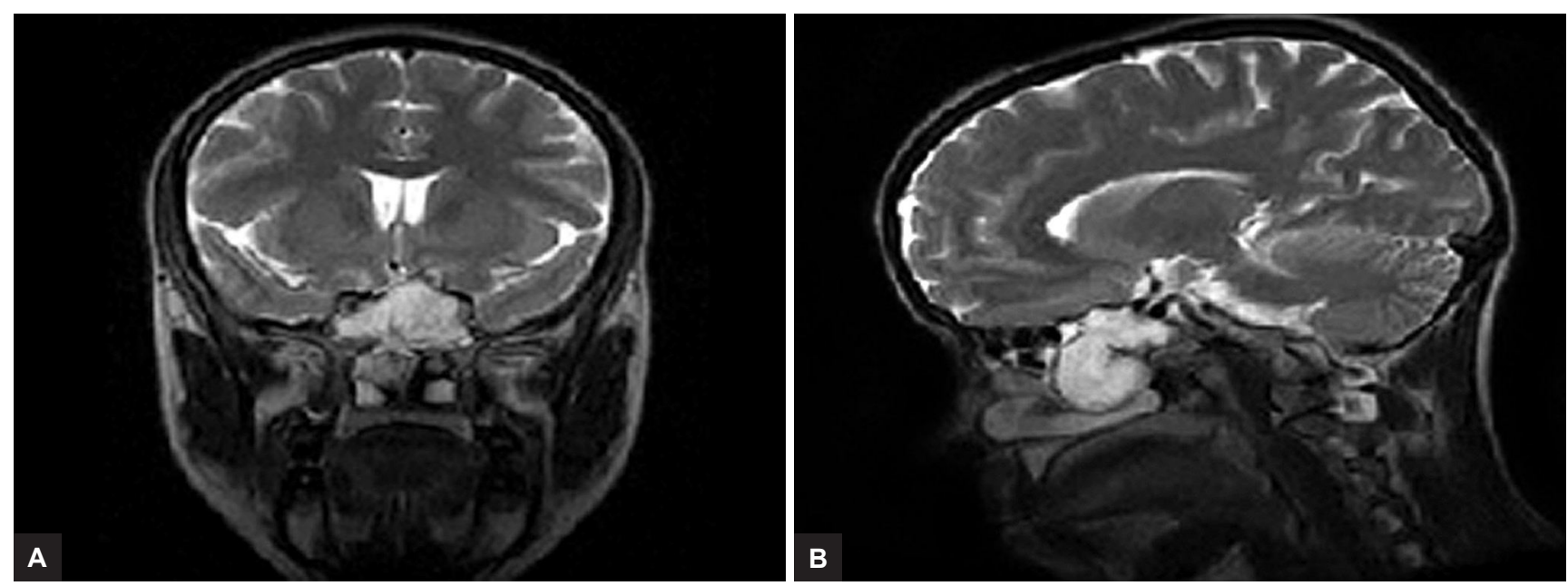

Figs 2A and B: T2-weighted image of MRI brain with PNS showing benign looking mass correlating with the CT findings. Also optic nerves were compressed, which was more in left side 


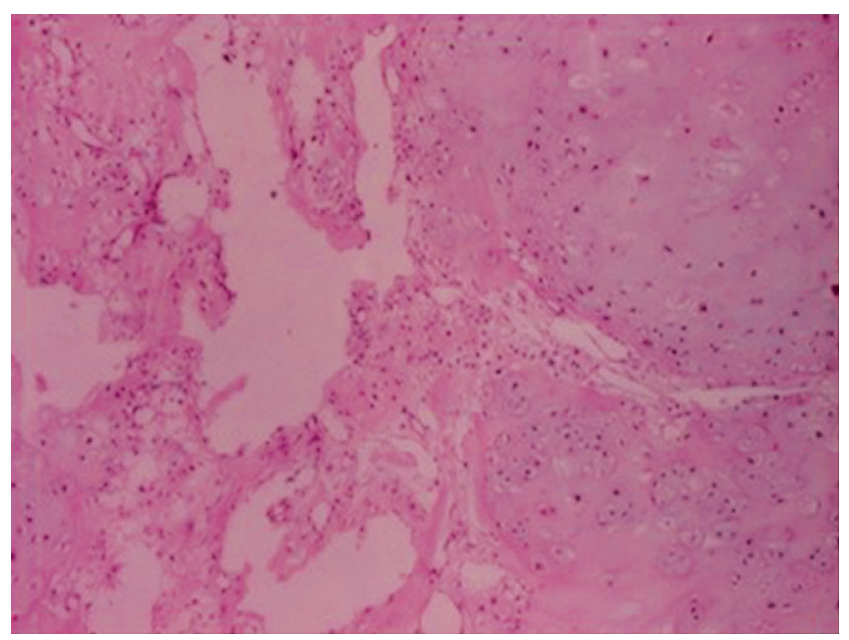

Fig. 3: Histopathological slide of the patient

the $\mathrm{CT}, 2,11,12$ and on MRI examination, they are typically isointense to hypointense on T1-weighted imaging and hyperintense on T2-weighted imaging and typically show heterogeneous enhancement, which helps to distinguish it from meningiomas and schwannomas. ${ }^{2,12}$

On histopathological analysis of the surgical specimen, clival chordomas show fluid and mucoid substance with hemorrhagic and necrotic areas within the tumor. In some cases, calcification and bone sequestrations can also be found. ${ }^{1,10,13-15}$

Immunohistochemical staining shows positive staining for S100, Vimentin, Cytokeratin, carcinoembryonic antigen, and epithelial membrane antigen (positivity only in chondroid differentiation).

Radical resection with or without radiotherapy of clival chordomas has been recommended by many researchers for better results, ${ }^{16}$ and radiotherapy can be given to recurrent cases. ${ }^{2,17}$ Approach to the clival region has always remained a challenge for the surgeons over a period of time. Transbasal, orbitozygomatic, subtemporal, transcondylar, transmaxillary, and extended transsphenoidal techniques have been proposed in the past. ${ }^{16,18,19}$ With the development of nasal endoscopic surgery, EEA has been developed as it takes advantage of the natural sinus route and may provide a minimally invasive approach for these midline tumors. ${ }^{1,5,9,20}$ This EEA shows almost equivalent results to extensive approaches. ${ }^{21,22}$ The complication of CSF leak can be managed with local flap repair techniques. Hence, this approach should be in the surgery of choice for the management of clival chordomas. $^{20-22}$

Conventional radiotherapy with high-energy photons at a dose of 60 to 65 Gy may offer temporary benefit in disease control in patients with inadequate surgery or recurrence or as exclusive treatment for inoperable disease. $^{22}$
Prognosis of the tumor is typically poor, due to the locally aggressive nature of these tumors, with the 10-year survival approximately $40 \% .^{2,17,22}$

\section{CONCLUSION}

Endoscopic endonasal surgery is the safe and reliable approach of clival chordoma tumor resection. It is a minimally invasive procedure and should be considered as a preferential approach to conventional surgical method.

\section{REFERENCES}

1. Little RE, Taylor RJ, Miller JD, Ambrose EC, Germanwala AV, Sasaki-Adams DM, Ewend MG, Zanation AM. Endoscopic endonasal transclival approaches: case series and outcomes for different clival regions. J Neurol Surg B Skull Base 2014 Aug;75(4):247-254.

2. Weerakkody Y, Gaillard F, Pituitary region masses. Eur Soc Radio 2014:1-31.

3. al-Mefty O, Borba LA. Skull base chordomas: a management challenge. J Neurosurg 1997 Feb;86(2):182-189.

4. Ferraresi V, Nuzzo C, Zoccali C, Marandino F, Vidiri A, Salducca N, Zeuli M, Giannarelli D, Cognetti F, Biagini R. Chordoma: clinical characteristics, management and prognosis of a case series of 25 patients. BMC Cancer 2010 Jan;10:22.

5. Tan NC, Naidoo Y, Oue S, Alexander H, Robinson S, Wickremesekera A, Floreani S, Vrodos N, Santoreneos S, Ooi E. Endoscopic surgery of skull base chordomas. J Neurol Surg B Skull Base 2012 Dec;73(6):379-386.

6. Brunworth J, Lin T, Keschner DB, Garg R, Lee JT. Use of the Hadad-Bassagasteguy flap for repair of recurrent cerebrospinal fluid leak after prior transsphenoidal surgery. Allergy Rhinol (Providence) 2013 Fall;4(3):e155-161.

7. Deconde AS, Sanaiha Y, Suh JD, Bhuta S, Bergsneider M, Wang MB. Metastatic disease to the clivus mimicking clival chordomas. J Neurol Surg B Skull Base 2013 Oct;74(5):292-299.

8. Ammirati M, Bernardo A. Management of skull base chordoma. Crit Rev Neurosurg 1999 Mar;9(2):63-69.

9. Cavallo LM, Cappabianca P, Messina A, Esposito F, Stella L, de Divitiis E, Tschabitscher M. The extended endoscopic endonasal approach to the clivus and cranio-vertebral junction: anatomical study. Childs Nerv Syst 2007 Jun;23(6): 665-671.

10. Chambers PW, Schwinn CP. Chordoma. A clinicopathologic study of metastasis. Am J Clin Pathol 1979 Nov;72(5): 765-776.

11. Jahangiri A, Chin AT, Wagner JR, Kunwar S, Ames C, Chou D, Barani I, Parsa AT, McDermott MW, Benet A, et al. Factors predicting recurrence after resection of clival chordoma using variable surgical approaches and radiation modalities. Neurosurgery 2015 Feb;76(2):179-185.

12. Oot RF, Melville GE, New PF, Austin-Seymour M, Munzenrider J, Pile-Spellman J, Spagnoli M, Shoukimas GM, Momose KJ, Carroll R, et al. The role of MR and CT in evaluating clival chordomas and chondrosarcomas. AJR Am J Roentgenol 1988 Sep;151(3):567-575.

13. Gay E, Sekhar LN, Rubinstein E, Wright DC, Sen C, Janecka IP, Snyderman $\mathrm{CH}$. Chordomas and chondrosarcomas of the cranial base: results and follow-up of 60 patients. Neurosurgery 1995 May;36(5):887-897. 
14. Hazarika D, Kumar RV, Muniyappa GD, Mukherjee G, Rao CR, Narasimhamurthy NK, Shenoy AM, Nanjundappa. Diagnosis of clival chordoma by fine needle aspiration of an oropharyngeal mass. A case report. Acta Cytol 1995 May-Jun;39(3): 507-510.

15. O'Connell JX, Renard LG, Liebsch NJ, Efird JT, Munzenrider JE, Rosenberg AE. Base of skull chordoma. A correlative study of histologic and clinical features of 62 cases. Cancer 1994 Oct;74(8):2261-2267.

16. Romero FR, Listik S. Endoscopic endonasal approach for clival chordomas - case report and review of literature. J Bras Neurocirurg 2012;23(1):61-64.

17. Carrabba G, Dehdashti AR, Gentili F. Surgery for clival lesions: open resection versus the expanded endoscopic endonasal approach. Neurosurg Focus 2008;25(6):E7.
18. Fahlbusch, R.; Buchfelder, M. The transsphenoidal approach to invasive sellar and clival lesions. In: Sekhar LN, Janecka IP, editors. Surgery of cranial base tumors. New York: Raven Press, Ltd., 1993. p. 337-349.

19. Sekhar, LN.; Janecka, IP., editors. Surgery of cranial base tumors. New York: Raven Press; 1993. p. 337-349.

20. Uttley D, Moore A, Archer DJ. Surgical management of midline skull-base tumors: a new approach. J Neurosurg 1989 Nov;71(5 Pt 1):705-710.

21. Stippler M, Gardner PA, Snyderman CH, Carrau RL, Prevedello DM, Kassam AB. Endoscopic endonasal approach for clival chordomas. Neurosurgery 2009 64:268-278

22. Dehdashti AR, Karabatsou K, Ganna A, Witterick I, Gentili F. Expanded endoscopic endonasal approach for treatment of clival chordomas: early results in 12 patients. Neurosurgery 2008 Aug;63(2):299-307. 